ALBERT DONNAY'S DISCLAIMER FOR THIS PREPRINT, 3/31/2020, V1

1. This preprint was submitted to medrxiv.org on 3/31/2020.

2. This preprint is not peer-reviewed or published.

3. Any use you make of the information in this preprint is at your own risk.

4. This preprint was written by a toxicologist for educational purposes.

5. This preprint is not intended as substitute for the medical advice of a physician.

If you are having a medical emergency in North America, call 911; otherwise call 112.

\title{
Title
}

\section{COVID-19 morbidity and mortality caused by endogenous carbon monoxide poisoning, with recommendations for testing and treatment}

\author{
Running Title
}

COVID-19 and carbon monoxide

\section{Author}

Albert Donnay*1

1. Donnay Detoxicology LLC, Hyattsville MD, USA

\section{*Correspondence}

email: albert@donnaydetox.com

\begin{abstract}
To test our hypothesis that abnormal levels of endogenous carbon monoxide (CO) produced naturally by heme oxygenase-1 (HO-1) in response to infections of all kinds may be contributing to the morbidity and mortality associated with COVID-19, we searched PubMed for peer-reviewed literature on carbon monoxide and each of eleven abnormal blood tests, fourteen signs and symptoms, and five fatal complications of COVID-19 infection reported in a case series from a hospital in Wuhan, China: acute respiratory distress syndrome (ARDS), acute kidney injury, acute cardiac injury, arrhythmia, and shock. We found reports of acute exogenous $\mathrm{CO}$ poisoning causing all the same signs, symptoms and complications, and all the abnormal blood tests except D-dimer and procalcitonin. Our search also found endogenous HO-1 and CO levels correlated with these complications, independent of any inhaled $\mathrm{CO}$ exposure. In sharp contrast to the $\mathrm{CO}$ poisoning literature, most studies of endogenous $\mathrm{CO}$ interpret its close positive correlation with these acute conditions as protective, with some going so far as to recommend treating ARDS with inhaled CO. We conclude with new recommendations for testing endogenous CO poisoning in COVID-19 cases using devices approved by the US Food and Drug Administration that can distinguish $\mathrm{CO}$ coming from the lungs, arteries, veins, and average of all tissues, unlike current protocols for $\mathrm{CO}$ poisoning that only measure $\mathrm{CO}$ in arteries or veins but not both. Based on these findings, we appeal to clinicians to start testing CO levels in COVID-19 patients and to stop monitoring oxygen saturation with conventional pulse oximeters that overestimate oxygen saturation by the sum of carboxyhemoglobin and methemoglobin. We conclude by reviewing FDA-approved treatments that may help COVID-19 patients with endogenous CO poisoning. These include zinc-based drugs that lower the rate of endogenous CO production by inhibiting HO-1, and drug-free devices and methods that reduce the total body burden of $\mathrm{CO}$ after exogenous $\mathrm{CO}$ poisoning.
\end{abstract}




\section{Introduction}

All types of infections studied to date, both bacterial and viral, including coronaviruses, trigger an increase in the activity of the heme oxygenase-1 (HO-1) enzyme that catabolizes heme proteins which are not fully oxygenated into equal parts of carbon monoxide (CO), molecular iron, and biliverdin, the precursor of bilirubin [Yachie 2003i]. Many researchers have shown this natural response to infections is beneficial in many ways [Hill-Batorski 2013] [Bunse 2015], including against such diverse viruses as HIV, Hepatitis C, and Ebola [Singh 2018].

We hypothesize that, as with fever, rising levels of endogenous CO may go too far and quickly turn deadly if they overwhelm the normally modest ability of key organs to absorb, metabolize, and excrete CO without failing. While there are no reports to date of abnormal CO levels in COVID-19 patients, we believe this is only because health care providers have not yet had a high enough "index of suspicion" to test for this possibility.

We fear health professionals and their patients are being misled by conventional pulse oximeters that hospitals and other health care facilities around the world use to monitor oxygen levels. As the operating manuals of these devices warn and many studies warn, conventional pulse oximeters cannot distinguish between hemoglobin bound with CO or oxygen (O2) [Pretto 2014]. What they display as SpO2 or O2Sat is actually the sum of the fraction of oxygen bound to hemoglobin as measured by blood gas analyzers plus both carboxyhemoglobin (COHb) and methemoglobin. The latest warning published in March 2020 comes from a study of over 1100 simultaneous SaO2 and SpO2 measurements done on patients receiving extra-corporeal membrane oxygen (ECMO) treatment. The authors found "SpO2 often overestimates SaO2 by substantial margins" and concluded "clinicians should be wary of the reliability of continuous pulse oximetry to assess oxygenation" [Nasar 2020].

This is not a problem when monitoring non-smokers who have normal $\mathrm{COHb}$ under one percent. But this can be a fatal oversight when CO levels in blood and tissues are either high and only falling slowly, as occurs in people with recent exogenous $\mathrm{CO}$ exposure and abstinent smokers, or high and still rising, which occurs when the primary source(s) are endogenous and upregulated by a disease process or other stressor.

Given that higher than normal levels of endogenous $\mathrm{CO}$ have been reported in all kinds of infections as well as in fevers, acute respiratory distress syndrome, cardiac arrhythmia, renal failure, and sepsis (Table 3), it seems reasonable to hypothesize that COVID-19 patients are being continuously exposed to high levels of CO and all the more if they develop one or more of these complications. Our hypothesis can be readily tested by simply checking CO levels in COVID-19 cases using any of several FDA-approved devices and methods already widely sold to medical professionals and the public for consumer use. Many are non-invasive and give results in real time, with little or no sampling cost.

Specifically, we hypothesize that:

1. COVIDS-19 cases and casualties have more $\mathrm{CO}$ in their arteries and veins than uninfected healthy people; and 2. the severity of COVID-19 cases correlates positively with the magnitude of the arterial-venous CO difference and the total body burden of $\mathrm{CO}$ in the average of all tissues.

We further hypothesize that COVID-19 cases with higher than normal CO will benefit from treatments documented to benefit cases of:

3. prior exogenous CO poisoning, when this exposure has stopped and the total CO body burden is falling; and

4. current endogenous $\mathrm{CO}$ poisoning, when high exposure is continuing from upregulated heme oxygenase-1.

Lastly and, by the same logic, we hypothesize that treatments documented to have high rates of bad outcomes for cases of acute exogenous CO poisoning, such as mechanical ventilation [Simonsen 2018], will be similarly harmful for COVID-19 cases. From this toxicologist's perspective, the ventilator crisis is not that hospitals may run out of them, but that ventilators may be making COVID-19 patients worse.

Counter-intuitively, we believe the problem is not too much CO in the lungs of COVID-19 patients, but too little. Studies show $\mathrm{CO}$ in the lungs is protective against infections within a limited range, but that both low and high $\mathrm{COHb}$ are associated with decreased survival. We suspect mechanical ventilation and hyperoxygenation treatments are keeping free CO levels in the lungs of COVID-19 patients artificially low, while raising the level in blood and other organs where free $\mathrm{CO}$ is more harmful. Critically, studies show arterial $\mathrm{COHb}$ rises with each additional day patients 
are on mechanical ventilators and the level correlates with mortality [Chawla 2019]. In addition, the partial pressure of their arterial oxygen keeps falling as their arterial free $\mathrm{CO}$ and $\mathrm{COHb}$ keep rising [Ascha 2018].

\section{Methods}

To assess the extent of overlap between the abnormal lab tests, signs, symptoms and complications of COVID-19 with those of carbon monoxide poisoning, we selected for comparison an early report on 138 hospitalized COVID19 cases from Wuhan, China, published in JAMA Network [Wang 2020]. We then searched the US National Library of Medicine via www.PubMed.gov for literature on "carbon monoxide" and each of the signs, symptoms and complications reported there, as well as for each blood test whose average result among the patients treated in intensive care was significantly higher (or in the case of lymphocyte count, smaller) than the other COVID-19 patients.

For each outcome for which some overlap with exogenous CO poisoning was found, we selected a representative study from the peer-reviewed literature. We then searched PubMed to find information on options for testing and treating carbon monoxide poisoning, and again selected a representative reference for each. In cases where more than one matching study was available, we selected the study with the largest number of subjects.

\section{Results}

We found nine of the eleven blood test abnormalities seen in COVID-19 ICU cases in the literature on exogenous CO poisoning (Table 1), missing only the tests for D-dimer and procalcitonin. We also found all fourteen COVID-19 signs and symptoms (Table 2), and all five potentially fatal complications (Table 3 ) in CO literature.

Table 1. Abnormal Blood Tests in COVID-19 cases also reported in cases of exogenous CO poisoning

\section{Abnormal Blood Tests}

1.1 Alanine aminotransferase

1.2 Bilirubin

1.3 BUN

1.4 Creatinine kinase-MB

1.5 D-dimer

1.6 Hypersensitive Troponin I

1.7 Lactate dehydrogenase

1.8 Lymphocyte count

1.9 Neutrophils

1.10 Procalcitonin

1.11 WBC, total examples of reports in cases of Exogenous CO Poisoning

Shen 2015

Cervellin 2015

Shen 2015

Shen 2015

none found in CO literature via PubMed

Shen 2015

Penney 1976

Moon 2019

Moon 2019

none found in CO literature via PubMed

Shen 2015

Table 2. Abnormal signs and symptoms in COVID-19 also reported in cases of exogenous CO poisoning

\section{Signs and Symptoms (\% among 36 Wuhan examples of reports in cases of cases in ICUs) Exogenous CO Poisoning}

2.1 Abdominal Pain

2.2 Anorexia

2.3 Diarrhea

2.4 Dizziness

2.5 Dry Cough

\section{Mortelmans 2015}

Katz 1958

Foster 1999 (a pediatric case)

Creswell 2015, also in Mortelmans 2015

Creswell 2015, also in Foster 1999, Kahan 2007 
2.6 Dyspnea

2.7 Expectoration (hemoptysis)

2.8 Fatigue

2.9 Fever

2.10 Headache

2.11 Myalgia (chest pain)

2.12 Nausea

2.13 Pharyngalgia

2.14 Vomiting
(63.9)
Creswell 2015, also in Foster 1999, Kahan 2007

Kahan 2007

Mortelmans 2015

Ku 2015

Creswell 2015, also in Foster 1999, Mortelmans 2015

Creswell 2015, also in Kahan 2007

Creswell 2015, also in Mortelmans 2015

Creswell 2015

Creswell 2015, also in Mortelmans 2015

Table 3. Complications of COVID-19 correlated with both exogenous and endogenous CO exposure

\section{Complications}

\section{(\% among 36 Wuhan cases in ICUs)}

3.1 Acute Cardiac Injury

3.2 ARDS

3.3 Arrhythmia

3.4 Acute Kidney Injury

3.5 Shock

\section{examples correlated with Exogenous CO Poisoning and seen as harmful}
(19.6)

\section{examples correlated with Endogenous $\mathrm{CO}$ from $\mathrm{HO}-1$ and seen as protective}

\author{
Ayer 2016 \\ Sheu 2009 \\ Rosa 2012 \\ Csongradi 2012 \\ Larsen 2010
}

In sharp contrast to the reports of exogenous $\mathrm{CO}$ poisoning causing these complications, we found many more linking the complications with rising levels of endogenous $\mathrm{HO}-1$ and $\mathrm{CO}$, which the authors of these studies interpret as protective.

\section{Discussion}

The previously unreported overlap of COVID-19 and CO poisoning outcomes that we document here is extraordinary, unlikely due to chance, and obviously not due to an epidemic outbreak of exogenous CO poisoning. It extends even to complications not reported in this case series from Wuhan but by others later, such as pneumonia [Zhang 2020]. This is reported as both an outcome of acute exogenous CO poisoning [Al-Moamary 2000] and as disease whose severity is modulated by endogenous CO even in the absence of any exogenous exposure [Gahlot 2017].

There is clearly sufficient evidence for the CO hypothesis to warrant testing CO levels in people with various stages of COVID-19. If their CO levels are in abnormal disequilibrium compared to healthy controls and higher in patients on mechanical ventilation, this will have critical implications for the testing and treatment of COVID-19 going forward.

Clinicians will need to stop relying on conventional pulse oximeters to monitor oxygen saturation, and start testing people with infectious disease for endogenous CO poisoning using methods that can distinguish the levels in lungs, arteries, veins and the average of all tissues [Donnay 2016a]. Options for testing and treating endogenous CO poisoning are discussed below.

\section{a. Options for testing endogenous $\mathrm{CO}$ poisoning}

Several kinds of FDA-approved CO measuring devices are available to test for exogenous poisoning that can be adapted to test for endogenous poisoning. Some are sold only to medical laboratories and health care professionals and others to the public-primarily people trying to quit smoking (Table 4). All of them can be used with our breath-holding method to distinguish levels of $\mathrm{CO}$ in more than just the one compartment that each is designed to measure (Donnay 2019a]. 
Table 4. Types of CO measuring devices approved by the US FDA

CO Measuring Device Limit of Detection Brands Sold in USA

4.1 Blood Gas Analyzers $0.1 \% \mathrm{COHb}$ too many to list
with CO oximetry capability
owned by clinical laboratories and minority of hospitals in USA

4.2 Breath CO Analyzers $\quad 0.1$ or $1 \mathrm{ppm} \mathrm{CO} \quad$ Carrot Pivot, COvita iCO, MedSpiro MicroCO owned by minority of hospitals, first responders, and people in smoking cessation programs

(Note any $\mathrm{CO}$ monitor that displays accurately from $1 \mathrm{ppm}$ and fits in a plastic bag can measure exhaled $\mathrm{CO}$ )

4.4 Pulse CO Oximeters $\quad 0.1 \% \mathrm{SpCO}^{\circledR}(1) \quad{\text { Masimo Rad } 57^{\circledR}}^{\circledR}$

used by majority of fire departments in USA

4.4 Continuous Pulse CO Oximeters $0.1 \% \mathrm{SpCO}^{\oplus}(1) \quad$ Masimo Radical $7^{\circledR}$ with rainbow ${ }^{\circledR}$ SET sensor used by majority of hospitals in USA, but typically only during surgeries with general anesthesia

Table 4, footnote 1. $\mathrm{SpCO}^{\circledR}$ stands for saturation percent $\mathrm{CO}$ which is an arterial measure. The pulse oximeters that measure this transcutaneously are the only devices that can display the level of $\mathrm{COHb}$ separately from oxygenated hemoglobin, instead of including it with methemoglobin in an overestimate of oxygen saturation as conventional pulse oximeters display. Masimo announced on 23 March 2020 that it was offering financial incentives to its customers during the COVID-19 pandemic to encourage more use of the rainbow ${ }^{\circledast}$ SET sensor's ability to measure hemoglobin and nitric oxide, but CO was not mentioned [Masimo 2020].

Breath $\mathrm{CO}$ analyzers offer the greatest flexibility in this regard. They are typically designed to measure only the level of $\mathrm{CO}$ diffusing from veins after 20 seconds of breath-holding, but simply by repeating the procedure with different breath-holding times, it is possible to distinguish the levels of free diffusing from the lungs after 0 seconds, from arteries after 5 , and the average of all tissues beyond the lungs after 35 [Donnay 2019b].

With pulse $\mathrm{CO}$ oximeters, the first measures are reversed, so the arterial $\mathrm{SpCO}$ im is displayed at 0 seconds while the level of $\mathrm{CO}$ in the lower lung follows after 5 seconds. In either case, if the display remains constant through all 35s, it shows the levels of free $\mathrm{CO}$ in all these compartments are in relatively healthy equilibrium.

When using a blood gas analyzer, the breath holding is done when the blood samples are drawn, so that one venous puncture can collect two tubes of blood: the original venipuncture is left in place for 20 seconds before a second tube is collected. The first gives the venous $\mathrm{CO}$ level and the second reflects the level of CO diffusing from the average of all tissues.

One shortcoming of blood and breath $\mathrm{CO}$ analyzers is that, unless repeated over time or monitored continuously, they cannot distinguish whether a high CO level in blood, breath or skin is the result of some prior exposure(s) that are now gradually being excreted, or the result of ongoing endogenous exposures, which may be rising or falling. But tests for bilirubin (BR) IX alpha in serum and indirect BR can, because these increase in step only with endogenous CO. Conveniently, BR levels correlate well with both arterial $\mathrm{COHb}$ and exhaled CO levels among critically ill patients [Morimatsu 2006].

While all hospitals in the US can draw blood for CO testing in their emergency departments (EDs), a regional survey of acute care hospitals in the Pacific Northwest found more than half cannot analyze them in-house and have to send them out for analysis [Hampson 2006]. This step adds one to three days which is too slow for acute care settings. Few US hospitals are yet using non-invasive breath $\mathrm{CO}$ analyzers or standalone pulse $\mathrm{CO}$ oximeters that give results in less than a minute, although most are already using continuous transcutaneous pulse $\mathrm{CO}$ oximeters in their operating rooms, where they are connected to the patient monitor during surgery. They are intended to 
alert anesthesiologists if the $\mathrm{CO}$ that accumulates in closed-loop ventilation systems during long surgeries approaches dangerous levels so they can flush the circuit.

We urge hospitals with these continuous pulse CO oximeters to start using them to test CO levels in all their COVID-19 patients. Since hospitals do not have enough for every patient, they may need to use them as roving spot check devices.

Hospitals without any non-invasive means to check CO will have to make do with arterial and venous blood tests for carboxyhemoglobin ( $\mathrm{COHb}$ ). They are needlessly invasive, painful, inaccurate, hard to replicate and slow. But they are nevertheless better than nothing provided that venous and arterial samples are taken in quick succession from the same area so the magnitude and direction of the gap between them can be determined.

One advantage of arterio-venous blood testing is that it does not require breath-holding to determine the size and direction of the $\mathrm{COHb}$ gap, which indicates whether someone is net absorbing $\mathrm{CO}$ (from air and/or lungs), net excreting it, or in healthy equilibrium.

Outside hospitals, most first responders already own pulse CO oximeters and/or breath CO analyzers that they could use to measure CO in the COVID-19 cases they are being called on to transport. It would be preferable if they could do this before they put COVID-19 patients on supplemental oxygen, as this will start to shift CO from their arterial hemoglobin to arterial plasma and from there into organs beyond the lungs.

The only type of CO detectors sold to the public for breath analysis are meant to be used as part of smoking cessation programs to give smokers more incentive to quit. But they can be used by non-smokers, as well, of course, and by anyone who wants to monitor their exhaled CO levels. Current models connect to smartphone-based applications and allow users to both track their results over time and share them with others.

If initial testing finds any abnormally high (or low) level of CO in lungs, arteries, veins or the average of all tissues, at least one more of these compartments should be tested before making treatment decisions to determine the magnitude and direction of any unhealthy disequilibrium. These variables can make a large difference in the odds of surviving acute $\mathrm{CO}$ poisoning, as shown in post-mortem $\mathrm{COHb}$ levels published by the Office of the Maryland Medical Examiner [Levine 2002]. These show that CO fatalities experience a very large arterio-venous (a-v) COHb difference before they die compared to healthy controls, whose (a-v) gap is less than $2 \%$ absolute. Among CO victims who died while the level of $\mathrm{CO}$ in their tissues was still rising, their (a-v)COHb gaps were $8 \%$ to $27 \%$. But among those died while the level of $\mathrm{CO}$ in their tissues was falling, when venous $\mathrm{CO}$ was greater than arterial, the largest even briefly survivable gaps were only half as large, from $-4 \%$ to $+7 \%$.

We propose this clear distinction could be used to identify COVID-19 victims whose deaths were CO-related versus not. The same asymmetry is seen in less severely exposed survivors of exogenous CO poisoning. One study frequently cited in defense of the claim that the a-v COHb difference is not statistically significant in cases of acute CO poisoning overlooked the clinical significance of a-v gaps it reported in the range $+7 \%$ to $-3 \%$ [Touger 1995$]$.

\section{b. Options for treating endogenous $\mathrm{CO}$ poisoning}

For treating exogenous CO poisoning, most current protocols focus on only two options: either 100\% oxygen or hyperbaric oxygen, assisted as needed by mechanical ventilation [O'Malley 2018]. Unfortunately, both methods raise the risk of delayed neurological sequelae compared to other options because they so effectively displace CO from arterial hemoglobin into plasma and from there into tissues [Donnay 2017]. Once beyond blood, free CO may bind to and disable any of many vital heme proteins, including myoglobins, neuroglobins, cytoglobins, and cytochromes, all of which is much more disruptive of normal physiology than simply leaving CO reversibly bound to $\mathrm{Hb}$ in blood where it is much less harmful, at least below 50\% [Goldbaum 1976]

That the CO-related signs, symptoms and complications are more severe in mechanically ventilated and hyperoxygenated COVID-19 patients suggests these treatments may be driving free CO from the lungs via blood into other organs. Counter-intuitively but consistent with the literature that finds increasing levels of endogenous $\mathrm{CO}$ are therapeutic for the same complications, we hypothesize that treatments focused on lowering the total body burden of $\mathrm{CO}$ will have better outcomes if they leave some in the lungs rather than flushing CO to zero. This 
is supported by studies showing that both non-surgical ICU patients have a U-shaped survival curve: both low and high $\mathrm{COHb}$ are significantly correlated with lower survival [Fazekas 2012],[Melley 2005]

For options, we point clinicians to over forty other treatments for CO poisoning for which successful trials in humans or other animals have been published [Donnay 2017]. Given that liver and kidney function are typically impaired in survivors of $\mathrm{CO}$ poisoning, we believe it is safer to treat CO poisoning with methods that can reduce the total CO body burden without drugs and so not increase metabolic demands on CO-impaired liver and kidneys (Table 5).

Table 5. Drug-free treatments for exogenous CO poisoning

\subsection{ECMO = Extra-Corporeal Membrane Oxygenation (FDA approved unless noted)}

a. ECMO is designed to diffuse oxygen into blood while allowing carbon dioxide to diffuse out, but it also releases free $\mathrm{CO}$, even as $\mathrm{COHb}$ increases an average of $0.006 \%$ per hour while on ECMO [Nissar 2020].

b. eliminates need for paralysis, intubation, and mechanical ventilation

c. although patients with higher $\mathrm{COHb}(>3 \%)$ need longer ECMO-mean 244 versus 98 hours [Nissar 2020]both venoarterial [Teerapuncharoen 2015] and venoveno [McCunn 2000] ECMO have rescued CO poisoning survivors after unsuccessful mechanical ventilation progressed to multi-organ failure and refractory hypoxemia suggesting ECMO should be tried first for $\mathrm{CO}$ cases.

d. porcine study shows ECMO greatly outperforms mechanical ventilation for treatment of cardiogenic shock from acute CO poisoning: 0 of 6 deaths versus 5 of 6 [Simonsen 2018]

e. similar EC systems exist for carbon dioxide release (ECCO2R) and carbon monoxide release (ECCORS), but the latter is designed to add CO to blood for therapeutic purposes, not extract it [Wollborn 2018]

5.2 ECCOR-P = Extra-Corporeal Carbon Monoxide Removal with Phototherapy (not FDA approved)

a. combines ECMO-like passive diffusion membrane for $\mathrm{CO}, \mathrm{CO} 2$ and oxygen with red light

b. $\mathrm{COHb}$ clearance is $2 \mathrm{x}$ rate in healthy lungs and $3 \mathrm{x}$ in injured lungs versus inhaling $100 \% 02$ [Zazzeron 2019]

5.3 Therapeutic Phlebotomy (FDA approved but not for CO poisoning)

a. only CO treatment that removes both free and heme-bound CO from blood [Gordon-Watson 1925]

b. also practiced in acupuncture [Yue 2015]

c. reduces high iron and high bilirubin

d. improves pulmonary gas exchange [Cruz 1979]

\subsection{Isocapnic and Hypercapnic Ventilation Devices [Takeuchi 2000]}

a. simplest devices mix rebreathed carbon dioxide with fresh air, as occurs inside snorkels [Toklu 2003] and partial rebreather masks [Donnay 2016b]

b. more complex mix carbon dioxide from tank with oxygen line [Fisher 2011], as occurs inside Clearmate ${ }^{\mathrm{TM}}$ device from Thornhill Medical that the US FDA approved in 2019 to treat CO poisoning in Emergency Departments

c. Note Thornhill Medical is not promoting the Clearmate ${ }^{\mathrm{TM}}$ for treatment of COVID-19 cases but is instead selling its "circle-circuit" ventilator for this purpose even though the circuit has no CO sensor, alarm or scrubber.

5.5 Red Light Therapy at wavelengths of 630 to $660 \mathrm{~nm}$ (FDA approved but not for CO poisoning)

a. releases $\mathrm{CO}$ from heme proteins

b. works invasively inside lungs [Zazzeron 2017] or externally, with light against skin

c. other applications included relieving muscle pain, cramps, rashes, cough, headaches, and sore throats

5.6 Sunbathing in natural or artificial light (the latter is FDA approved for treatment of hyperbilirubinemia)

a. hastens excretion of free CO through skin; enhanced by ingesting riboflavin [Vreman 2009]

b. increases vitamin D synthesis and, via UVc radiation, kills viruses on skin and other surfaces 
Mechanical ventilation combined with high flow or hyperbaric oxygen are not recommended because they are not effective for survivors of $\mathrm{CO}$ poisoning. In a series of 81 cases reported from Taiwan, $50.6 \%$ suffered bad outcomes, including 11\% who died [Kao 2009]. These rates are in the same range as those reported for COVID-19 patients on ventilators.

Before treating anyone with high CO in their lungs, arteries, veins or tissues, it is important to know where it is coming from. In people with COVID-19, a high level could be the result of some prior exogenous CO poisoning, but CO levels in such cases are relatively stable day to day or decline slowly as the CO absorbed into tissues in the past gradually diffuses back out into venous blood, which leaves a small negative gap in arterio-venous CO levels.

In sharp contrast, if an individual's CO level is rising day to day, it is much more likely part of their body's natural response to an infection or other disease process and thus more likely to be beneficial than not, like a fever. As such, we recommend that the rising endogenous $\mathrm{CO}$ be managed the same way, and that clinicians not flush $\mathrm{CO}$ from the lungs with hyperoxygenation but instead allow some modest and tolerable rise in CO within therapeutic ranges [Fredenburgh 2018].

Only if someone has $\mathrm{CO}$ levels and $\mathrm{CO}$ symptoms that keep increasing beyond tolerable levels would we urge taking aggressive steps, before complications arise, to either reduce the total body burden of CO (Table 5) and/or their rate of new $\mathrm{CO}$ production. The latter can be achieved with a variety of zinc compounds that downregulate HO-1 (Table 6).

Table 6. Treatments for endogenous $\mathrm{CO}$ poisoning that inhibit $\mathrm{HO}-1$

\subsection{Zinc compounds [Read 2019]}

these doses reduced severity and duration of the common cold, a coronavirus

6.1.a Zinc Acetate, 9 or $13 \mathrm{mg}$, every 2 to 3 hours when awake from start to end of illness

6.1.b Zinc Gluconate/Glycine, 13 or $24 \mathrm{mg}$, with same instructions

\subsection{Metalloporphryins [Podalicka 2018]}

all are competitive inhibitors; last 2 are water soluble; none FDA approved except for research

6.2.a Chromium, Tin and Zinc Deuteroporphyrins

6.2.b Chromium, Tin and Zinc Mesoporphyrins

6.2.c Chromium, Tin and Zinc Protoporphyrins

6.2.d Polyethylene Glycol Zinc Protoporphyrin

6.2.e Styrene Maleic Acid Zinc Protoporphyrin

\subsection{Imidazole-based compounds [Podalicka 2018]}

all are non-competitive inhibitors and water-soluble; none FDA approved except for research

6.3.a QC-1, aka Azalanstat

6.3.b QC-13

6.3.c QC-30

Most significantly, two such compounds have already been shown in human trials to safely and significantly reduce both the severity and duration of symptoms caused by another coronavirus, the common cold. They are distributed in USA with the FDA's approval as zinc acetate (brand name Galzin, which is available only by prescription from Teva Pharmaceuticals), or without FDA approval as zinc gluconate, which is sold as an over the counter supplement under many brand names. Both come in capsules up to $50 \mathrm{mg}$ with instructions to start taking them every two to three hours as soon as you notice the onset of flu-like symptoms, which would require about 70 capsules per week.

We recommend trials of zinc supplements that we predict will be effective in limiting the severity and duration of COVID-19 morbidity. But we also warn people not to take zinc supplements before developing CO symptoms (unless needed for some other medical reason). This is because if the zinc acts as intended and depresses the 
protective effects of HO-1 activity, studies of people and animals with genetic polymorphisms in HO-1 activity show they are more likely to both contract and succumb to systemic infections [Gahlot 2017],[Saukkonnen 2012].

\section{Conclusions}

We have shown that 14 signs and symptoms and 5 frequently fatal complications of COVID-19 infection reported in a representative series of hospitalized cases from Wuhan, China, are all also reported in the peer-reviewed literature on $\mathrm{CO}$ poisoning. All the complications are each also independently associated with increases in endogenous $\mathrm{CO}$. These findings are consistent with the hypotheses that endogenous carbon monoxide is causing the signs, symptoms and complications of COVID-19 but they do not prove it, which will require appropriate testing of cases and controls. Fortunately, FDA-approved devices for non-invasive spot and continuous testing of $\mathrm{CO}$ levels in real time are already widely distributed among hospitals and fire departments.

We conclude that people with COVID-19 who have labs, signs, symptoms, and complications consistent with endogenous $\mathrm{CO}$ poisoning should be tested for this possibility with any device that can measure CO reproducibly in lungs, blood and tissues.

We also urge clinicians worldwide to stop relying on conventional pulse oximeters to monitor oxygen saturation since the display is always overestimated by unknown fractions of $\mathrm{COHb}$ and $\mathrm{MetHb}$.

For people with abnormally high levels of $\mathrm{CO}$ in their lungs, blood, and/or tissues, we recommend treatments that either quickly lower the total body burden of $\mathrm{CO}$ without drugs, or which quickly reduce the rate of endogenous $\mathrm{CO}$ production, while boosting ventilation if needed with carbon dioxide mixtures. This should exclude mechanical ventilation, high-flow hyperoxygenation, and hyperbaric because all increase the level of CO in tissues.

Our approach will not cure COVID-19 infections but we predict it will reduce morbidity and mortality and eliminate the need for mechanical ventilators.

\section{Acknowledgments}

The author thanks Paige Gossage, PhD, Victoria Pennachia, Phillip Porter, PE, Jim Spath, and Lynnea S. Wright, DC, FASA, for their invaluable editorial assistance at all hours of day and night, and Mina for her company when the editors were asleep. He also thanks Hartmut Schneider, MD, PhD, of the Johns Hopkins Sleep Disorders Center for collaborating on studies of CO-related devices and methods from 2016-2017.

\section{Funding}

None.

\section{Competing Interests}

Donnay holds US patent 10386357B2 for his breath-holding method but authorizes its unrestricted royalty-free non-commercial use. He has no financial or competing interests in any of the named companies or compounds.

\section{References}

Al-Moamary MS, Al-Shammary AS, Al-Shimemeri AA, Ali MM, Al-Jahdali HH, Awada AA. Complications of carbon monoxide poisoning. Saudi Med J. 2000 Apr;21(4):361-3. PubMed PMID: 11533819.

Ascha M, Bhattacharyya A, Ramos JA, Tonelli AR. Pulse Oximetry and Arterial Oxygen Saturation during Cardiopulmonary Exercise Testing. Med Sci Sports Exerc. 2018 Oct;50(10):1992-1997. doi:

10.1249/MSS.0000000000001658. PubMed PMID: 29771822; PubMed Central PMCID: PMC6138536.

Ayer A, Zarjou A, Agarwal A, Stocker R. Heme Oxygenases in Cardiovascular Health and Disease. Physiol Rev. 2016 Oct;96(4):1449-508. doi:10.1152/physrev.00003.2016. Review. PubMed PMID: 27604527; PubMed Central PMCID: PMC5504454.

Bunse CE, Fortmeier V, Tischer S, Zilian E, Figueiredo C, Witte T, Blasczyk R, Immenschuh S, Eiz-Vesper B. Modulation of heme oxygenase-1 by metalloporphyrins increases anti-viral T cell responses. Clin Exp Immunol. 
2015 Feb;179(2):265-76. doi: 10.1111/cei.12451. PubMed PMID: 25196646; PubMed Central PMCID:

PMC4298404.

Cervellin G, Comelli I, Buonocore R, Picanza A, Rastelli G, Lippi G. Serum bilirubin value predicts hospital admission in carbon monoxide-poisoned patients. Active player or simple bystander? Clinics (Sao Paulo). 2015 Sep;70(9):62831. doi: 10.6061/clinics/2015(09)06. PubMed PMID: 26375565; PubMed Central PMCID:

PMC4557572.

Chawla A, Ray S, Matettore A, Peters MJ. Arterial carboxyhaemoglobin levels in children admitted to PICU: A retrospective observational study. PLoS One. 2019 Mar 7;14(3):e0209452. doi: 10.1371/journal.pone.0209452. eCollection 2019. PubMed PMID: 30845230; PubMed Central PMCID: PMC6405068.

Creswell PD, Meiman JG, Nehls-Lowe H, Vogt C, Wozniak RJ, Werner MA, Anderson H. Exposure to Elevated Carbon Monoxide Levels at an Indoor Ice Arena-Wisconsin, 2014. MMWR Morb Mortal Wkly Rep. 2015 Nov 20;64(45):1267-70. doi:10.15585/mmwr.mm6445a3. PubMed PMID: 26583915.

Cruz JC, Diaz C, Marticorena E, Hilario V. Phlebotomy improves pulmonary gas exchange in chronic mountain polycythemia. Respiration. 1979;38(6):305-13. PubMed PMID: 538338.

Csongradi E, Juncos LA, Drummond HA, Vera T, Stec DE. Role of carbon monoxide in kidney function: is a little carbon monoxide good for the kidney? Curr Pharm Biotechnol. 2012 May;13(6):819-26. Review. PubMed PMID: 22201605; PubMed Central PMCID: PMC3354025.

Donnay A 2019a. Interpretation of gas levels measured via breath, blood and skin after different breath-holding times. US Patent US10386357B2. Issue date 20 August 2019. Accessed 2020 March 27.

https://patents.google.com/patent/US10386357B2/en

Donnay A. 2019b. Breath holding times distinguish gases diffusing from lungs, arteries, veins and the average of all tissues. Owlstone International Breath Biopsy Conference, Cambridge UK. Accessed 2020 March 27.

https://osf.io/dmua4/

Donnay A, Schneider S. 2016a. New protocols proposed for the testing, triage and treatment of CO poisoning using emergency medical equipment. Poster. First CO Summit of the VT-NH Carbon Monoxide Alliance, Lebanon, NH. Accessed 2020 March 27. https://osf.io/5gzx7/

Donnay A, Schneider S. 2016b. Partial rebreather masks that increase minute ventilation could accelerate exhalation of inhaled anesthesia and shorten recovery time. Poster. New York Academy of Sciences Conference on Surgery and Cognition, NYC, NY. Accessed 2020 March 27. https://osf.io/8rwz2/

Donnay A, Schneider S. 2017. Rethinking the treatment of carbon monoxide poisoning from the 1800 s to present. Poster. Society of Toxicology, Baltimore, MD. Accessed 2020 March 27. https://osf.io/qfbz6/

Fazekas AS, Wewalka M, Zauner C, Funk GC. Carboxyhemoglobin levels in medical intensive care patients: a retrospective, observational study. Crit Care. 2012 Jan 11;16(1):R6. doi: 10.1186/cc11138. PubMed PMID: 22236404; PubMed Central PMCID: PMC3396235.

Fisher JA, Iscoe S, Fedorko L, Duffin J. Rapid elimination of CO through the lungs: coming full circle 100 years on. Exp Physiol. 2011 Dec;96(12):1262-9. doi:10.1113/expphysiol.2011.059428. Epub 2011 Oct 3. PubMed PMID: 21967899; PubMed Central PMCID: PMC3274699.

Foster M, Goodwin SR, Williams C, Loeffler J. Recurrent acute life-threatening events and lactic acidosis caused by chronic carbon monoxide poisoning in an infant. Pediatrics. 1999 Sep;104(3):e34. PubMed PMID: 10469817.

Fredenburgh LE, Perrella MA, Barragan-Bradford D, Hess DR, Peters E, Welty-Wolf KE, Kraft BD, Harris RS, Maurer R, Nakahira K, Oromendia C, Davies JD, Higuera A, Schiffer KT, Englert JA, Dieffenbach PB, Berlin DA, Lagambina S, 10 
Bouthot M, Sullivan AI, Nuccio PF, Kone MT, Malik MJ, Porras MAP, Finkelsztein E, Winkler T, Hurwitz S, Serhan CN, Piantadosi CA, Baron RM, Thompson BT, Choi AM. A phase I trial of low-dose inhaled carbon monoxide in sepsisinduced ARDS. JCI Insight. 2018 Dec 6;3(23). pii: 124039. doi: 10.1172/jci.insight.124039.PubMed PMID: 30518685; PubMed Central PMCID: PMC6328240.

Gahlot S, Nasreen N, Johnson JA, Sahn SA, Mohammed KA. Heme Oxygenase-1Deficiency Diminishes MethicillinResistant Staphylococcus aureus Clearance Due to Reduced TLR9 Expression in Pleural Mesothelial Cells. PLoS One. 2017 Jan 4;12(1):e0169245. doi: 10.1371/journal.pone.0169245. eCollection 2017. PubMed PMID: 28052108; PubMed Central PMCID: PMC5215390.

Gao Y, Yang J, Ma L, Zhang Y, Li Z, Wu L, Yang L, Wang H. Non-ST elevation myocardial infarction induced by carbon monoxide poisoning: A case report. Medicine (Baltimore). 2019 Apr;98(15):e15151. doi: 10.1097/MD.0000000000015151. PubMed PMID: 30985691; PubMed Central PMCID: PMC6485747.

Goldbaum LR, Orellano T, Dergal E. Mechanism of the toxic action of carbon monoxide. Ann Clin Lab Sci. 1976 JulAug;6(4):372-6. PubMed PMID: 962299.

Gordon-Watson C. Venesection and blood transfusion in carbon monoxide poisoning. Br Med J. 1925 Dec 5;2(3388):1049-50. PubMed PMID: 20772248; PubMed Central PMCID: PMC2227900.

Hampson NB, Scott KL, Zmaeff JL. Carboxyhemoglobin measurement by hospitals: implications for the diagnosis of carbon monoxide poisoning. J Emerg Med. 2006 Jul;31(1):13-6. PubMed PMID: 16798147

Hill-Batorski L, Halfmann P, Neumann G, Kawaoka Y. The cytoprotective enzyme heme oxygenase-1 suppresses Ebola virus replication. J Virol. 2013 Dec;87(24):13795-802. doi: 10.1128/JVI.02422-13. Epub 2013 Oct 9. PubMed PMID: 24109237; PubMed Central PMCID: PMC3838215

Kahan ES, Martin UJ, Spungen S, Ciccolella D, Criner GJ. Chronic cough and dyspnea in ice hockey players after an acute exposure to combustion products of a faulty ice resurfacer. Lung. 2007 Jan-Feb;185(1):47-54. Epub 2007 Feb 9. PubMed PMID: 17294334.

Kai Man C, Koon Ngai L. Endogenous carbon monoxide production in extracorporeal membrane oxygenationrelated hemolysis: potential use of point-of-care CO-oximetry carboxyhemoglobin to detect hemolysis. Clin Case Rep. 2018 Jan 3;6(2):346-349. doi: 10.1002/ccr3.1351. eCollection 2018 Feb. PubMed PMID: 29445475; PubMed Central PMCID: PMC5799617.

Kao HK, Lien TC, Kou YR, Wang JH. Assessment of myocardial injury in the emergency department independently predicts the short-term poor outcome in patients with severe carbon monoxide poisoning receiving mechanical ventilation and hyperbaric oxygen therapy. Pulm Pharmacol Ther. 2009 Dec;22(6):473-7. doi:

10.1016/j.pupt.2009.04.006. Epub 2009 Apr 22. PubMed PMID: 19393326.

Ku CH, Hung HM, Leong WC, Chen HH, Lin JL, Huang WH, Yang HY, Weng CH, Lin CM, Lee SH, Wang IK, Liang CC, Chang CT, Lin WR, Yen TH. Outcome of patients with carbon monoxide poisoning at a far-east poison center. PLoS One. 2015 Mar 6;10(3):e0118995. doi: 10.1371/journal.pone.0118995. eCollection 2015. PubMed PMID: 25745854; PubMed Central PMCID: PMC4352004.

Levine B, Moore KA, Titus JM, Fowler D. A comparison of carboxyhemoglobin saturation values in postmortem heart blood and peripheral blood specimens. J Forensic Sci. 2002 Nov;47(6):1388-90. PubMed PMID: 12455669.

Masimo. In response to blood shortages due to COVID-19, Masimo offers licenses for rainbow ${ }^{\circledR}$ noninvasive blood constituent monitoring, including total hemoglobin, $\mathrm{SpHb}^{\circledR}$, at no additional charge during the Coronavirus pandemic. 2020 March 23. Press Release. Irvine, CA: Masimo 
McCunn M, Reynolds HN, Cottingham CA, Scalea TM, Habashi NM. Extracorporeal support in an adult with severe carbon monoxide poisoning and shock following smoke inhalation: a case report. Perfusion. 2000 Mar;15(2):16973. Review. PubMed PMID: 10789573.

Moon JM, Chun BJ, Cho YS, Lee SM. Diagnostic Value of Parameters Related to White Blood Cell Counts for Troponin I Elevation in CO Poisoning. Cardiovasc Toxicol. 2019 Aug;19(4):334-343. doi: 10.1007/s12012-01809501-w. PubMed PMID: 30610672.

Morimatsu H, Takahashi T, Maeshima K, Inoue K, Kawakami T, Shimizu H, Takeuchi M, Yokoyama M, Katayama H, Morita K. Increased heme catabolism in critically ill patients: correlation among exhaled carbon monoxide, arterial carboxyhemoglobin, and serum bilirubin IXalpha concentrations. Am J Physiol Lung Cell Mol Physiol. 2006 Jan;290(1):L114-9. Epub 2005 Aug 12. PubMed PMID: 16100291.

Mortelmans LJ, Populaire J, Desruelles D, Sabbe MB. Mass carbon monoxide poisoning at an ice-hockey game: initial approach and long-term follow-up. Eur J Emerg Med. 2013 Dec;20(6):408-12. doi: 10.1097/MEJ.0b013e32835d1dcc. PubMed PMID: 23274717.

Melley DD, Finney SJ, Elia A, Lagan AL, Quinlan GJ, Evans TW. Arterial carboxyhemoglobin level and outcome in critically ill patients. Crit Care Med. 2007 Aug;35(8):1882-7. PubMed PMID: 17568332.

Meyer J, Prien T, Van Aken H, Bone HG, Waurick R, Theilmeier G, Booke M. Arterio-venous carboxyhemoglobin difference suggests carbon monoxide production by human lungs. Biochem Biophys Res Commun. 1998 Mar 6;244(1):230-2. PubMed PMID: 9514911.

Nisar S, Gibson CD, Sokolovic M, Shah NS. Pulse Oximetry Is Unreliable in Patients on Veno-Venous Extracorporeal Membrane Oxygenation Caused by Unrecognized Carboxyhemoglobinemia. ASAIO J. 2020 Mar 3. doi:

10.1097/MAT.0000000000001144. [Epub ahead of print] PubMed PMID: 32149749.

O’Malley GF, O’Malley RO. 2018. Carbon Monoxide Poisoning. Merck Manual, Professional Version.

Accessed 2020 March 27.

https://www.merckmanuals.com/professional/injuriespoisoning/poisoning/carbon-monoxide-

poisoning

Peng J, Lu R, Ye F, Deng HW, Li YJ. The heme oxygenase-1 pathway is involved in calcitonin gene-related peptidemediated delayed cardioprotection induced by monophosphoryl lipid A in rats. Regul Pept. 2002 Jan 15;103(1):1-7. PubMed PMID: 11738242.

Penney D, Maziarka T. Effect of acute carbon monoxide poisoning on serum lactate dehydrogenase and creatine phosphokinase. J Toxicol Environ Health. 1976 Jul;1(6):1017-21. PubMed PMID: 966312.

Petersen B, Ramackers W, Lucas-Hahn A, Lemme E, Hassel P, Queisser AL, Herrmann D, Barg-Kues B, Carnwath JW, Klose J, Tiede A, Friedrich L, Baars W, Schwinzer R, Winkler M, Niemann H. Transgenic expression of human heme oxygenase-1 in pigs confers resistance against xenograft rejection during ex vivo perfusion of porcine kidneys. Xenotransplantation. 2011 Nov-Dec;18(6):355-68. doi: 10.1111/j.1399-3089.2011.00674.x. Erratum in: Xenotransplantation. 2012 May-Jun;19(3):212. PubMed PMID: 22168142.

Podkalicka P, Mucha O, Józkowicz A, Dulak J, Łoboda A. Heme oxygenase inhibition in cancers: possible tools and targets. Contemp Oncol (Pozn). 2018 Mar;22(1A):23-32. doi: 10.5114/wo.2018.73879. Epub 2018 Mar 5. Review. PubMed PMID: 29628790; PubMed Central PMCID: PMC5885082.

Pretto JJ, Roebuck T, Beckert L, Hamilton G. Clinical use of pulse oximetry: official guidelines from the Thoracic Society of Australia and New Zealand. Respirology. 2014 Jan;19(1):38-46. doi: 10.1111/resp.12204. Epub 2013 Nov 20. Review. PubMed PMID: 24251722. 
Read SA, Obeid S, Ahlenstiel C, Ahlenstiel G. The Role of Zinc in Antiviral Immunity. Adv Nutr. 2019 Jul 1;10(4):696710. doi: 10.1093/advances/nmz013. PubMed PMID: 31305906; PubMed Central PMCID: PMC6628855.

Rosa AO, Movafagh S, Cleemann L, Morad M. Hypoxic regulation of cardiac Ca2+ channel: possible role of haem oxygenase. J Physiol. 2012 Sep 1;590(17):4223-37. doi: 10.1113/jphysiol.2012.236570. Epub 2012 Jul 2. PubMed PMID: 22753548; PubMed Central PMCID: PMC3473281.

Saukkonen K, Lakkisto P, Kaunisto MA, Varpula M, Voipio-Pulkki LM, Varpula T, Pettilä V, Pulkki K. Heme oxygenase 1 polymorphisms and plasma concentrations in critically ill patients. Shock. 2010 Dec;34(6):558-64. doi: 10.1097/SHK.0b013e3181e14de9. PubMed PMID: 20386498.

Schnittger V, Rosendahl K, Lind F, Palmblad J. Effects of carbon monoxide poisoning on neutrophil responses in patients treated with hyperbaric oxygen. J Investig Med. 2004 Dec;52(8):523-30. doi: 10.1136/jim-52-08-24. PubMed PMID: 15682684.

Shen CH, Peng CK, Chou YC, Pan KT, Chang SC, Chang SY, Huang KL. Predicting duration of mechanical ventilation in patients with carbon monoxide poisoning: a retrospective study. J Crit Care. 2015 Feb;30(1):19-24. doi: 10.1016/j.jcrc.2014.08.003. Epub 2014 Aug 10. PubMed PMID: 25194589.

Simonsen C, Magnusdottir SO, Andreasen JJ, Rohde MC, Kjærgaard B. ECMO improves survival following cardiogenic shock due to carbon monoxide poisoning - an experimental porcine model. Scand J Trauma Resusc Emerg Med. 2018 Nov 22;26(1):103. doi: 10.1186/s13049-018-0570-6. PubMed PMID: 30466470; PubMed Central PMCID: PMC6251161.

Singh N, Ahmad Z, Baid N, Kumar A. Host heme oxygenase-1: Friend or foe in tackling pathogens? IUBMB Life. 2018 Sep;70(9):869-880. doi: 10.1002/iub.1868. Epub 2018 May 14. Review. PubMed PMID: 29761622.

Takeuchi A, Vesely A, Rucker J, Sommer LZ, Tesler J, Lavine E, Slutsky AS, Maleck WH, Volgyesi G, Fedorko L, Iscoe S, Fisher JA. A simple "new" method to accelerate clearance of carbon monoxide. Am J Respir Crit Care Med. 2000 Jun;161(6):1816-9. PubMed PMID: 10852750.

Tanindi A, Yalcin R. Misdiagnosis of carbon monoxide intoxication in a patient with known coronary artery disease-a case report and review of cardiovascular effects of carbon monoxide poisoning. West Indian Med J. 2009 Nov;58(5):485-7. Review. PubMed PMID: 20441070.

Teerapuncharoen K, Sharma NS, Barker AB, Wille KM, Diaz-Guzman E. Successful treatment of Severe Carbon Monoxide Poisoning and Refractory Shock Using Extracorporeal Membrane Oxygenation. Respir Care. 2015 Sep;60(9):e155-60. doi:10.4187/respcare.03990. Epub 2015 Apr 28. PubMed PMID: 25922545.

Touger M, Birnbaum A, Wang J, Chou K, Pearson D, Bijur P. Performance of the RAD-57 pulse CO-oximeter compared with standard laboratory carboxyhemoglobin measurement. Ann Emerg Med. 2010 Oct;56(4):382-8. doi: 10.1016/j.annemergmed.2010.03.041. Epub 2010 Jun 3. PubMed PMID: 20605259.

Touger M, Gallagher EJ, Tyrell J. Relationship between venous and arterial carboxyhemoglobin levels in patients with suspected carbon monoxide poisoning. Ann Emerg Med. 1995 Apr;25(4):481-3. PubMed PMID: 7710152.

Vreman HJ, Knauer Y, Wong RJ, Chan ML, Stevenson DK. Dermal carbon monoxide excretion in neonatal rats during light exposure. Pediatr Res. 2009 Jul;66(1):66-9. doi: 10.1203/PDR.0b013e3181a7be77. PubMed PMID: 19342986; PubMed Central PMCID: PMC2714864.

Wang D, Hu B, Hu C, Zhu F, Liu X, Zhang J, Wang B, Xiang H, Cheng Z, Xiong Y, Zhao Y, Li Y, Wang X, Peng Z. Clinical Characteristics of 138 Hospitalized Patients With 2019 Novel Coronavirus-Infected Pneumonia in Wuhan, China. JAMA. 2020 Feb 7. doi: 10.1001/jama.2020.1585. [Epub ahead of print] PubMed PMID: 32031570; PubMed Central PMCID: PMC7042881. 
Wollborn J, Hermann C, Goebel U, Merget B, Wunder C, Maier S, Schäfer T, Heuler D, Müller-Buschbaum K, Buerkle $\mathrm{H}$, Meinel L, Schick MA, Steiger C. Overcoming safety challenges in CO therapy - Extracorporeal CO delivery under precise feedback control of systemic carboxyhemoglobin levels. J Control Release. 2018 Jun 10;279:336-344. doi: 10.1016/j.jconrel.2018.04.017. Epub 2018 Apr 12. PubMed PMID: 29655987.

Yachie A, Toma T, Mizuno K, Okamoto H, Shimura S, Ohta K, Kasahara Y, Koizumi S. Heme oxygenase-1 production by peripheral blood monocytes during acute inflammatory illnesses of children. Exp Biol Med (Maywood). 2003 May;228(5):550-6. PubMed PMID: 12709585.

Yue Y, Pan X, Zhang S, Jin J, Wang W, Wang D, Han D, Wang G, Hu Q, Kang J, Ding S, Yang Y, Bu H, Guo Y. A Randomized Controlled Trial of Puncturing and Bloodletting at Twelve Hand Jing Points to Treat Acute Carbon Monoxide Poisoning as Adjunct to First Aid Treatment: A Study Protocol. Evid Based Complement Alternat Med. 2015;2015:827305. doi: 10.1155/2015/827305. Epub 2015 Aug 3. PubMed PMID: 26339271; PubMed Central PMCID: PMC4538970.

Zazzeron L, Fischbach A, Franco W, Farinelli WA, Ichinose F, Bloch DB, Anderson RR, Zapol WM. Phototherapy and extracorporeal membrane oxygenation facilitate removal of carbon monoxide in rats. Sci Transl Med. 2019 Oct 9;11(513). pii: eaau4217. doi: 10.1126/scitranslmed.aau4217. PubMed PMID:31597752.

Zazzeron L, Liu C, Franco W, Nakagawa A, Farinelli WA, Bloch DB, Anderson RR, Zapol WM. Pulmonary Phototherapy to Treat Carbon Monoxide Poisoning in Rats. Shock. 2017 Jun;47(6):735-742. doi:

10.1097/SHK.0000000000000797. PubMed PMID: 27861257; PubMed Central PMCID: PMC5432394.

Zhang G, Zhang J, Wang B, Zhu X, Wang Q, Qiu S. Analysis of clinical characteristics and laboratory findings of 95 cases of 2019 novel coronavirus pneumonia in Wuhan, China: a retrospective analysis. Respir Res. 2020 Mar 26;21(1):74. doi: 10.1186/s12931-020-01338-8. PubMed PMID: 32216803; PubMed Central PMCID: PMC7099829.

\# \# \# 